\title{
PENGGUNAAN BENEISH RATIO INDEX DALAM PENDETEKSIAN FINANCIAL STATEMENT FRAUD
}

\author{
Oleh: Nurul Sa'adah Sarumpaet ${ }^{*}$, Kamilah $\mathbf{K}^{2}$ \\ nurulsaadah300@gmail.com ${ }^{1 *}$, kamilah@uinsu.ac.id ${ }^{2}$ \\ (Program Studi Akuntansi Syariah, FEBI UIN Sumatera Utara)
}

\begin{abstract}
Abstrak-Penelitian ini dilakukan bertujuan untuk mengetahui: 1) Persentase perusahaan manufaktur yang terdaftar di Bursa Efek Indonesia tahun 2017-2019 yang tergolong manipulators; 2) Persentase perusahaan manufaktur yang terdaftar di Bursa Efek Indonesia tahun 2017-2019 yang tergolong non manipulators; 3) Persentase perusahaan manufaktur yang terdaftar di Bursa Efek Indonesia tahun 2017-2019 yang tergolong grey company. Metode pengumpulan data menggunakan metode dokumentasi. Metode analisis data dengan deskriptif kuantitatif menggunakan rasio yang dikemukakan oleh Messod D.Beneish. Hasil penelitian menyimpulkan 1) Pada tahun 2017 terdapat 5,89\% perusahaan yang tergolong sebagai manipulators. Sedangkan tahun 2018 dan 2019 tidak terdapat perusahaan manipulators. 2) Pada tahun 2017 terdapat 52,94\%, tahun 2018 terdapat $41,17 \%$, tahun 2019 terdapat 70,59\% dari total perusahaan sampel yang tergolong non manipulators. 3) Pada tahun 2017 terdapat 41,17\%, tahun 2018 terdapat 58,83\%, tahun 2019 terdapat 29,41\% dari total perusahaan sampel tersebut yang tergolong sebagai grey company.
\end{abstract}

Kata Kunci: Beneish M-Score, Kecurangan Laporan Keuangan, Manipulators, Non Manipulators, Grey Company.

\begin{abstract}
This study was conducted to determine: 1) Percentage of manufacturing companies listed on the Indonesia Stock Exchange in 2017-2019 that are classified as manipulators; 2) Percentage of manufacturing companies listed on the Indonesia Stock Exchange in 2017-2019 that are classified as nonmanipulators; 3) Percentage of manufacturing companies listed on the Indonesia Stock Exchange in 2017-2019 that are classified as gray companies. Methods of data collection using the method of documentation. Methods of data analysis with quantitative descriptive using the ratio proposed by Messod D. Beneish. The results of the study conclude 1) In 2017 there were 5.89\% of companies classified as manipulators. While in 2018 and 2019 there were no manipulators companies. 2) In 2017 there were $52.94 \%$, in 2018 there were $41.17 \%$, in 2019 there were $70.59 \%$ of the total sample companies classified as non-manipulators. 3) In 2017 there were $41.17 \%$, in 2018 there were $58.83 \%$, in 2019 there were $29.41 \%$ of the total sample companies classified as gray companies.
\end{abstract}

Keywords: Beneish M-Score, Financial Statement Fraud, Manipulators, Non Manipulators, Gray Company. 


\section{PENDAHULUAN}

Setiap perusahaan mempunyai laporan keuangan yang bertujuan untuk menyediakan informasi yang menyangkut posisi keuangan, kinerja serta perubahan posisi keuangan suatu perusahaan yang bermanfaat bagi pemakai laporan keuangan dalam pengambilan keputusan ekonomi juga dapat menunjukkan pertanggungjawaban manajemen atas penggunaan sumbersumber daya yang dipercayakan kepada mereka. Menyadari pentingnya kandungan informasi dalam laporan keuangan tidak menutup kemungkinan dapat terjadi salah saji baik dikarenakan kekeliruan atau kecurangan oleh perilaku manajer perusahaan. Dampak yang timbul dari adanya kecurangan laporan keuangan adalah dapat mengurangi tingkat kepercayaan dan merugikan para pemangku kepentingan seperti kreditor, investor, karyawan, dan juga pemerintah. Apalagi disaat pandemic seperti sekarang ini, perusahaan-perusahaan sangat rentan untuk melakukan tindakan manipulasi, karena perusahaan tetap ingin menapatkan investor walaupun kondisi keuangan perusahaan sedang tidak stabil (Nasution et al., 2020).

Kecurangan (fraud) merupakan bentuk penipuan yang sengaja dilakukan sehingga menimbulkan kerugian tanpa disadari oleh pihak yang dirugikan tersebut dan memberikan keuntungan bagi pelaku kecurangan. Kecurangan laporan keuangan merupakan tindakan manipulasi terhadap isi laporan keuangan dengan tujuan untuk mendapatkan keuantungan secara pribadi dengan cara melebihlebihkan hasil usaha dan kondisi keuangan mereka, sehingga publik memberikan pandangan positif terhadap laporan keuangan yang telah mereka manipulasi.

Berdasarkan Report To The Nation Association of Certified Fraud Examiners, terdapat tiga jenis kasus kecurangan yang menjadi perhatian global yaitu Asset Misappropriation, Corruption dan Financial Statement Fraud. Dalam survai global yang dilakukan oleh ACFE (ACFE, 2018) pada tahun 2018, menyatakan bahwa kasus Penyalahgunaan Aset merupakan kasus kecurangan terbesar dengan persentase sebesar $89 \%$. Korupsi menempati posisi kedua setelah penyalahgunaan aset dengan persentase sebesar 38\%. Financial Statement Fraud (Kecurangan Laporan Keuangan) mendapatkan persentase sebesar 10\%. Meskipun Financial Statement Fraud mendapatkan persentase yang cukup rendah, namun tingkat kerugian yang ditimbulkan cukup tinggi yaitu sebesar $\$ 800.000$ pada tahun 2018.b Untuk kasus fraud di Indonesia, ACFE Chapter Indonesia (ACFE Indonesia Chapter \#111, 2016) berdasarkan temuan yang dilaporkan terakhir pada tahun 2016, diketahui 
bahwa di Indonesia kerugian terbesar adalah berasal dari tindak korupsi (77\%). Demikian juga halnya dengan penyalahgunaan aset mendapatkan persentase sebesar (19\%). Tindakan fraud yang menimbulkan kerugian terbesar adalah fraud laporan keuangan (4\%), dengan jumlah diatas Rp10milyar. Sesuai dengan temuan ACFE baik secara global maupun secara nasional dapat diketahui bahwa tindakan fraud laporan keuangan meskipun memiliki persentase kasus terkecil tetapi justru menimbulkan kerugian terbesar.

Skandal akuntansi mengenai financial statement fraud sangat marak terjadi. Kasus pemberian dana talangan Bank Century merupakan kasus terbesar yang merugikan negara dengan cara merampas uang negara lebih dari Rp. 7 Triliyun dalam bentuk bailout. Dalam kasus Bank Century tidak dilakukan oleh pejabat bank saja, namun melibatkan banyak pihak seperti aparat kepolisian, lembaga pembuat kebijakan perbankan bahkan beredar isu keterkaitan presiden dalam kasus tersebut. Kasus lain yang juga pernah terjadi adalah Toshiba melakukan penggelembungan keuntungan perusahaan. Kondisi keuangan Toshiba diduga menyimpang karena terjadi penggelembungan laba hingga US\$ 1,2 miliar selama tujuh tahun. Hal tersebut terjadi pada periode antara April 2008 hingga Maret 2014. Kasus tersebut terungkap sejak
April 2015 dan semakin memburuk pada Mei 2015 setelah komite independen mengambil alih evaluasi laporan keuangan, hal ini menyebabkan turunya saham Toshiba sekitar 20\% (Hantono, 2018).

Banyaknya skandal akuntansi yang terjadi merupakan salah satu alasan penting untuk dilakukannya analisis terhadap laporan keuangan untuk meminimalisir tindak kecurangan laporan keuangan serta dapat mendeteksi sejak dini adanya aktivitas kecurangan sebelum menjadi kasus besar yang dapat merugikan negara. Salah satu alat yang digunakan untuk mengetahui adanya manipulasi adalah dengan menggunakan benesih ratio index yang dipopulerkan oleh Beneish. .Alat deteksi yang digunakan dalam penelitian ini adalah Beneish $M$ Score dengan menggunakan lima variabel Days Sales in Receivable Index (DSRI), Gross Margin Index (GMI), Asset Quality Index (AQI), Sales Growth Index (SGI), dan Total Accrual To Total Assets Index (TATA). Penelitian ini memberikan sumbangan pemikiran mengenai pendeteksian kecurangan laporan keuangan dengan perhitungan beneish ratio index.

Menurut Sujarweni (Sujarweni, 2017) secara umum laporan keuangan adalah catatan informasi keuangan suatu perusahaan pada suatu periode akuntansi yang dapat digunakan untuk menggambarkan 
kinerja perusahaan dengan tujuan memberikan informasi keuangan perusahaan kepada pemilik, manajemen maupun pihak luar yang berkepentingan dengan laporan keuangan tersebut. Djarwanto (Djarwanto, 2010) menguraikan bahwa laporan keuangan adalah hasil dari proses akuntansi yang dapat digunakan sebagai alat untuk berkomunikasi dengan pihak-pihak yang berkepentingan dengan kondisi keuangan dan hasil operasi perusahaan.

Melalui laporan keuangan juga akan dapat dinilai kemampuan perusahaan untuk memenuhi seluruh kewajiban-kewajibannya baik jangka pendek maupun jangka panjang, struktur modal perusahaan, pendistribusian pada aktivanya, efektivitas dari penggunaan aktiva, pendapatan atau hasil usaha yang telah dicapai, beban-beban tetap yang harus dibayarkan oleh perusahaan serta nilai-nilai buku dari setiap lembar saham perusahaan yang bersangkutan.

Fraud atau yang sering dikenal dengan istilah kecurangan merupakan hal yang sekarang banyak dibicarakan di Indonesia. Pengertian fraud itu sendiri merupakan penipuan yang sengaja dilakukan, yang menimbulkan kerugian pihak lain dan memberikan keuntungan bagi pelaku kecurangan dan atau kelompoknya. Menurut $A C F E$, fraud dalam arti luas adalah segala upaya untuk mengelabui atau memperdaya pihak lain untuk mendapat manfaat (Priantara, 2013).

Menurut ACFE, bentuk kecurangan ataupun manipulasi yang bertujuan untuk mendapatkan keuntungan sepihak dan merugikan pihak lain terbagi menjadi 3, yaitu korupsi, penyalahgunaan aset, dan kecurangan laporan keuangan.

Beneish Ratio Index adalah suatu teknik yang digunakan untuk menganalisis laporan keuangan dalam mendeteksi ada atau tidaknya kecurangan laporan keuangan yang dikembangkan oleh Profesor Messod D Beneish. Hal tersebut dibuktikan oleh Beneish yang telah melakukan penelitian perbedaan uantitatif antara perusahaan yang terindentifikasi melakukan manipulasi laba dan yang tidak melakukan manipulasi laba. Beneish melakukan analisis dengan menggunakan data keuangan lalu menghitung rasio keuangan. Hal tersebut dilakukan untuk mengetahui apakah terdapat indikasi manipulasi terhadap laporan keuangan atau tidak.

Beneish mengungkapkan bahwa pada umumnya manipulasi laba ditunjukkan dengan peningkatan atas pendapatan atau penurunan atas beban perusahaan secara signifikan dari satu tahun (t) ke tahun sebelumnya (t-1).

Beneish M-Score diukur dengan menggunakan lima rasio dan telah dimodifikasi oleh beberapa peneliti bahwa kelima rasio model score tersebut menghasilkan hasil 
yang signifikan. Dalam penelitian sebelumnya, Roxas yang dikutip dari Abbas menegaskan bahwa model score, dengan lima rasio, dapat mengidentifikasi manipulasi laba lebih akurat daripada delapan rasio (Christy \& Stephanus, 2018).

\section{METODE PENELITIAN}

\section{Jenis dan Sumber Data Penelitian}

Jenis penelitian yang digunakan dalam penelitian ini adalah penelitian kuantitatif dengan pendekatan deskriptif. Berdasarkan data yang digunakan, penelitian ini menggunakan data kuantitatif yaitu data yang berbentuk angka dan mengacu pada perhitungan. Jenis data pada penelitian ini adalah data sekunder. Data sekunder mengacu pada informasi yang dikumpukan dari sumber-sumber yang sudah ada. Data-data yang digunakan dalam penelitian ini adalah laporan keuangan perusahaan manufaktur yang terdaftar di Bursa Efek Indonesia (BEI) Tahun 2017- 2019.

\section{Populasi dan Sampel}

Dalam penelitian ini populasi yang digunakan adalah seluruh perusahaan manufaktur yang listing di Bursa Efek Indonesia (BEI) yang mempublikasikan laporan keuangan (audited) pada tahun 2017-2019. Populasi berjumlah 154 perusahaan, diperoleh dari laporan keuangan di situs Bursa Efek Indonesia (BEI) www.idx.co.id.
Penentuan sampel dalam penelitian ini dilakukan dengan cara non probability - purposive sampling, dimana sampel ditentukan berdasarkan kriteria tertentu yang ditentukan penulis dan memiliki keterbatasan dalam hal generalisasi. Beberapa kriteria dalam penentuan sampel tersebut antara lain:

a. Perusahaan tersebut menerbitkan laporan keuangan konsolidasian (audited) dan mengumumkan laba per 31 Desember 20172019.

b. Perusahaan tesebut mengalami peningkatan penjualan.

c. Perusahaan tersebut mengalami peningkatan laba.

Dari kriteria yang telah ditentukan maka sampel yang berhasil penulis ambil adalah 17 perusahaan dengan rentang waktu penelitian 3 tahun sehingga total sampel keseluruhan adalah sebanyak 51 sampel.

\section{Definisi Operasional Variabel}

Variabel yang digunakan dalam penelitian ini adalah variabel tunggal yaitu deteksi kecurangan laporan keuangan dengan menggunakan Beneish Ratio Index. Menurut Beneish terdapat 5 (lima) variabel yang signifikan untuk memprediksi adanya manipulasi dalam laporan keuangan, variabelvariabel tersebut adalah:
a. Days Sales Receivables Index (DSRI)


DSRI merupakan rasio jumlah hari penjualan dalam piutang pada tahun pertama terjadinya manipulasi $D S R I=\frac{\left(\text { Account Receivable }_{t} / \text { Sales }_{t}\right)}{\left(\text { Account Receivable }_{t-1} / \text { Sales }_{t-1}\right)}$

b. Gross Margin Index (GMI)

GMI merupakan rasio gross margin tahun sebelumnya (tahun $\mathrm{t}-1$ )

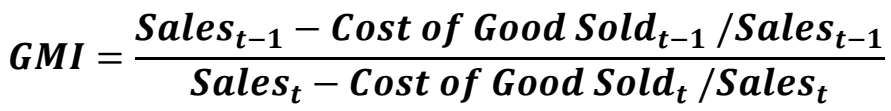

c. Asset Quality Index (AQI)

AQI merupakan rasio noncurrent assets (tidak termasuk property, plant, dan equipment) terhadap total kepastian. (tahun $\mathrm{t}$ ) terhadap pengukuran tahun sebelumnya (tahun t-1).

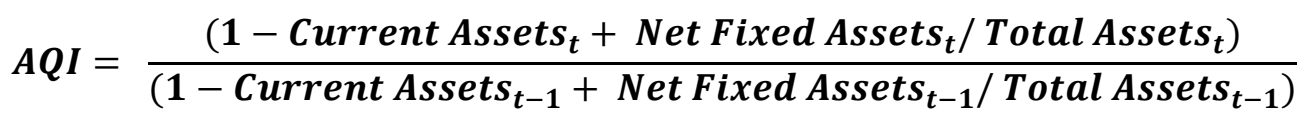

d. Sales Growth Index (SGI)

SGI merupakan rasio penjualan pada tahun pertama terjadinya manipulasi (tahun t) terhadap penjualan tahun sebelumnya (tahun $\mathrm{t}-1)$.

$S G I=\frac{\text { Sales }_{t}}{\text { Sales }_{t-1}}$ terhadap gross margin ta hun pertama terjadinya manipulasi (tahun t).

assets, yang mengukur proporsi total assets terhadap keuntungan di masa mendatang yang kurang memiliki

\section{TATA $=\frac{\text { Net Operating Profit }}{t / \text { Cash Flow From Operating }}$ Pral Assets $_{\text {Total }}$}

\section{Teknik Analisis Data}

Penelitian ini menggunakan teknik analisis ratio index terhadap data laporan keuangan perusahaan yang menjadi sampel penelitian. Langkah-langkah yang digunakan d. Total Accruals to Total Assets (TATA)

TATA merupakan rasio total accruals terhadap total assets. Dimana total accruals diperhitungkan sebagai perubahan akun modal kerja selain kas dan piutang pajak dikurangi depresiasi. 
b. Membandingkan indeks hitung dengan indeks parameter

(Beneish Ratio Index).

Tabel 1. Index Parameter Beneish

\begin{tabular}{|c|c|c|c|c|}
\hline \multirow{2}{*}{ No } & \multirow{2}{*}{$\begin{array}{c}\text { Indeks } \\
\text { Rasio }\end{array}$} & \multicolumn{3}{|c|}{ Indeks Parameter } \\
\hline & & Non Manipulators & Grey & Manipulators \\
\hline 1 & DSRI & $\leq 1,031$ & $1,031<$ index $<1,465$ & $\geq 1,465$ \\
\hline 2 & GMI & $\leq 1,014$ & $1,014<$ index $<1,193$ & $\geq 1,193$ \\
\hline 3 & AQI & $\leq 1,039$ & $1,039<$ index $<1,254$ & $\geq 1,254$ \\
\hline 4 & SGI & $\leq 1,134$ & $1,134<$ index $<1,607$ & $\geq 1,607$ \\
\hline 5 & DEPI & $\leq 1,001$ & $1,001<$ index $<1,077$ & $\geq 1,077$ \\
\hline 6 & SGAI & $\leq 1,054$ & $1,054<$ index $<1,041$ & $\geq 1,041$ \\
\hline 7 & LVGI & $\leq 1,037$ & $1,037<$ index $<1,111$ & $\geq 1,111$ \\
\hline 8 & TATA & $\leq 0,018$ & $0,018<$ index $<0,031$ & $\geq 0,031$ \\
\hline
\end{tabular}

Sumber: Data Primer yang diolah, 2021

c. Menentukan perusahaan tergolong manipulators atau non manipulators.

Adapun kriteria penggolongan untuk menentukan perusahaan yang tergolong manipulators, non manipulators atau grey company sebagai berikut:

1) Perusahaan yang memiliki $\geq$ 3 (tiga) indeks hitung yang sesuai dengan indeks parameter yang menyatakan Manipulators, tergolong ke dalam perusahaan Manipulators.

2) Perusahaan yang memiliki $\geq$ 3 (tiga) indeks hitung yang sesuai dengan indeks parameter yang menyatakan Non Manipulators, tergolong$$
\text { kedalam }
$$

$$
\text { perusahaan }
$$

Non

Manipulators.

3) Perusahaan yang memiliki $\geq$ 3 (tiga) indeks hitung yang sesuai dengan indeks parameter yang menyatakan grey, dan indeks hitung yang tidak memenuhi 2 (dua) kriteria penggolongan Manipulators dan Non Manipulators digolongkan perusahaan grey (Grey Company).

d. Menghitung jumlah persentase dari perusahaan yang tergolong manipulators atau non manipulators.

\section{HASIL DAN PEMBAHASAN}

\section{Hasil Penelitian}

a. Hasil Perhitungan DSRI dan Kategori Perusahaan 
Tabel 2. Tabel DSRI Tahun 2017-2019

\begin{tabular}{|c|c|c|c|c|c|c|c|}
\hline \multirow{2}{*}{ No } & \multirow{2}{*}{ Emiten } & \multicolumn{5}{|c|}{ DSRl } & \multicolumn{3}{|c|}{ Kategori } \\
\cline { 3 - 8 } & & 2017 & 2018 & 2019 & 2017 & 2018 & 2019 \\
\hline 1 & BUDI & 1,300793746 & 1,327656849 & 0,799252643 & $\mathrm{G}$ & $\mathrm{G}$ & $\mathrm{N}$ \\
\hline 2 & CLEO & 1,484613186 & 1,024275200 & 1,046202408 & $\mathrm{M}$ & $\mathrm{N}$ & $\mathrm{G}$ \\
\hline 3 & HOKI & 1,856728724 & 0,881918658 & 0,827492278 & $\mathrm{M}$ & $\mathrm{N}$ & $\mathrm{N}$ \\
\hline 4 & MYOR & 1,160204010 & 0,839375423 & 1,018183241 & $\mathrm{G}$ & $\mathrm{N}$ & $\mathrm{N}$ \\
\hline 3 & SKLT & 0,998782925 & 1,229228772 & 0,878949286 & $\mathrm{~N}$ & $\mathrm{G}$ & $\mathrm{N}$ \\
\hline 6 & STTP & 0,954104495 & 1,140023265 & 1,032407433 & $\mathrm{~N}$ & $\mathrm{G}$ & $\mathrm{G}$ \\
\hline 7 & GGRM & 0,976550592 & 0,673944517 & 0,941192945 & $\mathrm{~N}$ & $\mathrm{~N}$ & $\mathrm{~N}$ \\
\hline 8 & DVLA & 0,955326513 & 1,097121129 & 0,910594631 & $\mathrm{~N}$ & $\mathrm{G}$ & $\mathrm{N}$ \\
\hline 9 & KLBF & 1,049432870 & 1,083890193 & 1,021865418 & $\mathrm{G}$ & $\mathrm{G}$ & $\mathrm{N}$ \\
\hline 10 & SIDO & 1,158277290 & 0,891487769 & 1,166067568 & $\mathrm{G}$ & $\mathrm{N}$ & $\mathrm{G}$ \\
\hline 11 & WTON & 1,211678959 & 0,769671242 & 1,056195871 & $\mathrm{G}$ & $\mathrm{N}$ & $\mathrm{G}$ \\
\hline 12 & ARNA & 0,994754975 & 0,839743162 & 0,952978828 & $\mathrm{~N}$ & $\mathrm{~N}$ & $\mathrm{~N}$ \\
\hline 13 & MARK & 1,147647594 & 0,824514508 & 0,963402799 & $\mathrm{G}$ & $\mathrm{N}$ & $\mathrm{N}$ \\
\hline 14 & SRSN & 0,773950095 & 1,166687354 & 1,058073679 & $\mathrm{~N}$ & $\mathrm{G}$ & $\mathrm{G}$ \\
\hline 15 & AUTO & 1,052836020 & 0,933224434 & 1,020070751 & $\mathrm{G}$ & $\mathrm{N}$ & $\mathrm{N}$ \\
\hline 16 & SMSM & 0,908363865 & 1,036681183 & 1,088557816 & $\mathrm{~N}$ & $\mathrm{G}$ & $\mathrm{G}$ \\
\hline 17 & SRIL * & 1,129506501 & 0,763365212 & 1,183350789 & $\mathrm{G}$ & $\mathrm{N}$ & $\mathrm{G}$ \\
\hline
\end{tabular}

Sumber: Data Primer yang diolah, 2021

Dari hasil perhitungan Rasio Index DSRI terhadap 17 perusahaan sampel pada tahun 2017 ditemukan 2 perusahaan tergolong sebagai manipulators, 7 perusahaan tergolong sebagai non manipulators, dan 8 perusahaan tergolong sebagai grey company.

Dari hasil perhitungan Rasio Index DSRI terhadap 17 perusahaan sampel pada tahun 2018 terdapat 10 perusahaan tergolong sebagai non manipulators, dan 7 perusahaan tergolong sebagai grey company.

Dari hasil perhitungan Rasio Index DSRI terhadap 17 perusahaan sampel pada tahun 2019 terdapat 10 perusahaan tergolong sebagai nonmanipulators, dan 7 perusahaan tergolong sebagai grey company.

b. Hasil Perhitungan GMI dan Kategori Perusahaan

Tabel 3. Tabel GMI Tahun 2017-2019

\begin{tabular}{|c|c|c|c|c|c|c|c|}
\hline \multirow{2}{*}{ No } & \multirow{2}{*}{ Emiten } & \multicolumn{4}{|c|}{ GMI } & \multicolumn{3}{|c|}{ Kategoni } \\
\cline { 2 - 8 } & & 2017 & 2018 & 2019 & 2017 & 2018 & 2019 \\
\hline 1 & BUDI & 0,802308461 & 1,047568473 & 1,042929541 & $\mathrm{~N}$ & $\mathrm{G}$ & $\mathrm{G}$ \\
\hline 2 & CLEO & 0,822585933 & 1,136463655 & 0,887604859 & $\mathrm{~N}$ & $\mathrm{G}$ & $\mathrm{N}$ \\
\hline 3 & HOKI & 1,079249323 & 0,964272307 & 0,972207955 & $\mathrm{G}$ & $\mathrm{N}$ & $\mathrm{N}$ \\
\hline 4 & MYOR & 1,117408258 & 0,898967111 & 0,840375016 & $\mathrm{G}$ & $\mathrm{N}$ & $\mathrm{N}$ \\
\hline 5 & SKLT & 0,992331309 & 1,013503117 & 1,011696899 & $\mathrm{~N}$ & $\mathrm{~N}$ & $\mathrm{~N}$ \\
\hline 6 & STTP & 0,962159576 & 0,990491024 & 0,807911303 & $\mathrm{~N}$ & $\mathrm{~N}$ & $\mathrm{~N}$ \\
\hline 7 & GGRM & 0,995991753 & 1,122825057 & 0,945018067 & $\mathrm{~N}$ & $\mathrm{G}$ & $\mathrm{N}$ \\
\hline 8 & DVLA & 0,973281133 & 1,042040623 & 1,014022126 & $\mathrm{~N}$ & $\mathrm{G}$ & $\mathrm{N}$ \\
\hline 9 & KLBF & 1,007268967 & 1,040427486 & 1,032513504 & $\mathrm{~N}$ & $\mathrm{G}$ & $\mathrm{G}$ \\
\hline 10 & SIDO & 0,923164515 & 0,875803783 & 0,940854816 & $\mathrm{~N}$ & $\mathrm{~N}$ & $\mathrm{~N}$ \\
\hline 11 & WTON & 1,165373210 & 0,976425652 & 0,948622041 & $\mathrm{G}$ & $\mathrm{N}$ & $\mathrm{N}$ \\
\hline 12 & ARNA & 0,931796852 & 0,975856505 & 0,905746523 & $\mathrm{~N}$ & $\mathrm{~N}$ & $\mathrm{~N}$ \\
\hline 13 & MARK & 0,609754555 & 0,844303403 & 1,030517078 & $\mathrm{~N}$ & $\mathrm{~N}$ & $\mathrm{G}$ \\
\hline 14 & SRSN & 0,819280412 & 0,919998733 & 0,941015884 & $\mathrm{~N}$ & $\mathrm{~N}$ & $\mathrm{~N}$ \\
\hline 15 & AUTO & 1,116297766 & 1,062662739 & 0,860794977 & $\mathrm{G}$ & $\mathrm{G}$ & $\mathrm{N}$ \\
\hline 16 & SMSM & 1,075938927 & 0,993766438 & 1,001972637 & $\mathrm{G}$ & $\mathrm{N}$ & $\mathrm{N}$ \\
\hline 17 & SRIL & 0,947777518 & 1,268952437 & 0,892956358 & $\mathrm{~N}$ & $\mathrm{M}$ & $\mathrm{N}$ \\
\hline
\end{tabular}

Sumber: Data Primer yang diolah, 2021 
Dari hasil perhitungan GMI terhadap 17 perusahaan sampel pada tahun 2017 dapat diketahui bahwa 12 perusahaan sampel dikategorikan sebagai perusahaan non manipulators dan 5 perusahaan dikategorikan sebagai grey company.

Dari hasil perhitungan GMI terhadap 17 perusahaan sampel pada tahun 2018 dapat diketahui bahwa 1 perusahaan sampel dikategorikan sebagai perusahaan manipulators 10 perusahaan sampel dikategorikan sebagai perusahaan non manipulators dan 6 perusahaan dikategorikan sebagai grey company.

Dari hasil perhitungan GMI terhadap 17 perusahaan sampel pada tahun 2019 dapat diketahui bahwa 14 perusahaan sampel dikategorikan sebagai perusahaan non manipulators dan 3 perusahaan dikategorikan sebagai grey company.

c. Hasil Perhitungan AQI dan Kategori Perusahaan

Tabel 4. Tabel AQI Tahun 2017-2019

\begin{tabular}{|c|c|c|c|c|c|c|c|}
\hline \multirow{2}{*}{ No } & \multirow{2}{*}{ Emiten } & \multicolumn{4}{|c|}{$A Q I$} & \multicolumn{3}{|c|}{ Kategori } \\
\cline { 3 - 8 } & & 2017 & 2018 & 2019 & 2017 & 2018 & 2019 \\
\hline 1 & BUDI & 0,940613786 & 1,432755766 & 0,775067996 & $\mathrm{~N}$ & $\mathrm{M}$ & $\mathrm{N}$ \\
\hline 2 & CLEO & 1,667838443 & 1,377066510 & 1,212604453 & $\mathrm{M}$ & $\mathrm{M}$ & $\mathrm{G}$ \\
\hline 3 & HOKI & 2,137563786 & 1,219272562 & 0,985073023 & $\mathrm{M}$ & $\mathrm{G}$ & $\mathrm{N}$ \\
\hline 4 & MYOR & 1,221334657 & 1,184899968 & 1,010139586 & $\mathrm{G}$ & $\mathrm{G}$ & $\mathrm{N}$ \\
\hline 5 & SKLT & 1,199574436 & 1,335441040 & 1,060595503 & $\mathrm{G}$ & $\mathrm{M}$ & $\mathrm{G}$ \\
\hline 6 & STTP & 1,029866396 & 1,319435895 & 0,931723653 & $\mathrm{~N}$ & $\mathrm{M}$ & $\mathrm{N}$ \\
\hline 7 & GGRM & 1,043672275 & 1,034736588 & 1,150081846 & $\mathrm{G}$ & $\mathrm{N}$ & $\mathrm{G}$ \\
\hline 8 & DVLA & 1,099805230 & 1,023575587 & 1,063853852 & $\mathrm{G}$ & $\mathrm{N}$ & $\mathrm{G}$ \\
\hline 9 & KLBF & 1,049247246 & 1,060169341 & 1,053924403 & $\mathrm{G}$ & $\mathrm{G}$ & $\mathrm{G}$ \\
\hline 10 & SIDO & 0,907908224 & 0,950128860 & 1,108918316 & $\mathrm{~N}$ & $\mathrm{~N}$ & $\mathrm{G}$ \\
\hline 11 & WTON & 1,783397406 & 1,349162383 & 1,221131205 & $\mathrm{M}$ & $\mathrm{M}$ & $\mathrm{G}$ \\
\hline 12 & ARNA & 1,151344971 & 1,118074275 & 1,179155862 & $\mathrm{G}$ & $\mathrm{G}$ & $\mathrm{G}$ \\
\hline 13 & MARK & 1,444984278 & 1,210919284 & 1,417957362 & $\mathrm{M}$ & $\mathrm{G}$ & $\mathrm{M}$ \\
\hline 14 & SRSN & 0,877455400 & 1,060859595 & 1,198948465 & $\mathrm{~N}$ & $\mathrm{G}$ & $\mathrm{G}$ \\
\hline 15 & AUTO & 1,066200159 & 1,150164684 & 0,921988889 & $\mathrm{G}$ & $\mathrm{G}$ & $\mathrm{N}$ \\
\hline 16 & SMSM & 1,079568309 & 1,180670299 & 1,153492817 & $\mathrm{G}$ & $\mathrm{G}$ & $\mathrm{G}$ \\
\hline 17 & SRIL* & 1,706369693 & 1,094879056 & 1,266913185 & $\mathrm{M}$ & $\mathrm{G}$ & $\mathrm{M}$ \\
\hline
\end{tabular}

Sumber: Data Primer yang diolah, 2021

Dari hasil perhitungan $A Q I$ terhadap 17 perusahaan sampel pada tahun 2017 dapat diketahui bahwa 5 perusahaan tergolong manipulators, 4 perusahaan tergolong sebagai non manipulators dan 8 perusahaan tergolong sebagai grey company.

Dari hasil perhitungan $A Q I$ terhadap 17 perusahaan sampel pada tahun 2018 dapat diketahui bahwa 5 perusahaan tergolong manipulators, 3 perusahaan tergolong sebagai non manipulators dan 9 perusahaan tergolong sebagai grey company.

Dari hasil perhitungan $A Q I$ terhadap 17 perusahaan sampel pada tahun 2019 dapat diketahui bahwa 2 perusahaan tergolong manipulators, 
5 perusahaan tergolong sebagai non manipulators dan 10 perusahaan tergolong sebagai grey company. d. Hasil Perhitungan SGI dan Kategori Perusahaan

Tabel 5. Tabel SGI Tahun 2017-2019

\begin{tabular}{|c|c|c|c|c|c|c|c|}
\hline \multirow{2}{*}{ No } & \multirow{2}{*}{ Emiten } & \multicolumn{4}{|c|}{ SGI } & \multicolumn{3}{|c|}{ Kategon } \\
\cline { 3 - 8 } & & 2017 & 2018 & 2019 & 2017 & 2018 & 2019 \\
\hline 1 & BUDI & 1,017436302 & 1,054417748 & 1,134697140 & $\mathrm{~N}$ & $\mathrm{~N}$ & $\mathrm{~N}$ \\
\hline 2 & CLEO & 1,173199495 & 1,352097554 & 1,309919799 & $\mathrm{G}$ & $\mathrm{G}$ & $\mathrm{G}$ \\
\hline 3 & HOKI & 1,054344886 & 1,183234500 & 1,155331862 & $\mathrm{~N}$ & $\mathrm{G}$ & $\mathrm{G}$ \\
\hline 4 & MYOR & 1,134426127 & 1,155842785 & 1,040145672 & $\mathrm{~N}$ & $\mathrm{G}$ & $\mathrm{N}$ \\
\hline 5 & SKLT & 1,096346286 & 1,143122603 & 1,225913570 & $\mathrm{~N}$ & $\mathrm{G}$ & $\mathrm{G}$ \\
\hline 6 & STTP & 1,074664814 & 1,000547936 & 1,242505198 & $\mathrm{~N}$ & $\mathrm{~N}$ & $\mathrm{G}$ \\
\hline 7 & GGRM & 1,092190844 & 1,148869819 & 1,154806371 & $\mathrm{~N}$ & $\mathrm{G}$ & $\mathrm{G}$ \\
\hline 8 & DVLA & 1,085637548 & 1,078704154 & 1,066697553 & $\mathrm{~N}$ & $\mathrm{~N}$ & $\mathrm{~N}$ \\
\hline 9 & KLBF & 1,041699163 & 1,044206754 & 1,073984413 & $\mathrm{~N}$ & $\mathrm{~N}$ & $\mathrm{~N}$ \\
\hline 10 & SIDO & 1,004697467 & 1,073606751 & 1,110065096 & $\mathrm{~N}$ & $\mathrm{~N}$ & $\mathrm{~N}$ \\
\hline 11 & WTON & 1,540113943 & 1,292481915 & 1,022040745 & $\mathrm{G}$ & $\mathrm{G}$ & $\mathrm{N}$ \\
\hline 12 & ARNA & 1,146170739 & 1,137619575 & 1,091465923 & $\mathrm{G}$ & $\mathrm{G}$ & $\mathrm{N}$ \\
\hline 13 & MARK & 1,157135559 & 1,357344347 & 1,110830821 & $\mathrm{G}$ & $\mathrm{G}$ & $\mathrm{N}$ \\
\hline 14 & SRSN & 1,041838960 & 1,152460078 & 1,138900738 & $\mathrm{~N}$ & $\mathrm{G}$ & $\mathrm{G}$ \\
\hline 15 & AUTO & 1,058014970 & 1,133324211 & 1,005756174 & $\mathrm{~N}$ & $\mathrm{~N}$ & $\mathrm{~N}$ \\
\hline 16 & SMSM & 1,159759656 & 1,177663292 & 1,000624912 & $\mathrm{G}$ & $\mathrm{G}$ & $\mathrm{N}$ \\
\hline 17 & SRIL & 1,116790356 & 1,361619477 & 1,143033271 & $\mathrm{~N}$ & $\mathrm{G}$ & $\mathrm{G}$ \\
\hline
\end{tabular}

Sumber: Data Primer yang diolah, 2021

Dari hasil perhitungan SGI terhadap 17 perusahaan sampel pada tahun 2017 dapat diketahui bahwa 12 perusahaan dikategorikan sebagai non manipulators dan 5 perusahaan dikategorikan sebagai grey company.

Dari hasil perhitungan SGI terhadap 17 perusahaan sampel pada tahun 2018 dapat diketahui bahwa 6 perusahaan dikategorikan sebagai non manipulators dan 11 perusahaan dikategorikan sebagai grey company.

Dari hasil perhitungan $S G I$ terhadap 17 perusahaan sampel pada tahun 2019 dapat diketahui bahwa 10 perusahaan dikategorikan sebagai non manipulators dan 7 perusahaan dikategorikan sebagai grey company. e. Hasil Perhitungan Total Accruals to Total Assets (TATA) dan Kategori Perusahaan

Tabel 6. Tabel TATA Tahun 2017-2019

\begin{tabular}{|c|c|c|c|c|c|c|c|}
\hline \multirow{2}{*}{ No } & \multirow{2}{*}{ Emiten } & \multicolumn{3}{|c|}{ TATA } & \multicolumn{3}{|c|}{ Kategon } \\
\cline { 3 - 8 } & & 2017 & 2018 & 2019 & 2017 & 2018 & 2019 \\
\hline 1 & BUDI & $-0,006331444$ & $-0,033515081$ & $-0,046785634$ & $\mathrm{~N}$ & $\mathrm{~N}$ & $\mathrm{~N}$ \\
\hline 2 & CLEO & $-0,205293034$ & $-0,009061644$ & $-0,077550565$ & $\mathrm{~N}$ & $\mathrm{~N}$ & $\mathrm{~N}$ \\
\hline 3 & HOKI & 0,397484704 & $-0,034037323$ & 0,025161298 & $\mathrm{M}$ & $\mathrm{N}$ & $\mathrm{G}$ \\
\hline 4 & MYOR & 0,013023123 & 0,052366248 & $-0,000121038$ & $\mathrm{~N}$ & $\mathrm{M}$ & $\mathrm{N}$ \\
\hline 5 & SKLT & $-0,024149388$ & $-0,022148815$ & 0,002333561 & $\mathrm{~N}$ & $\mathrm{~N}$ & $\mathrm{~N}$ \\
\hline 6 & STIP & 0,040654415 & $-0,021232432$ & 0,019848769 & $\mathrm{M}$ & $\mathrm{N}$ & $\mathrm{G}$ \\
\hline 7 & GGRM & $-0,026129851$ & 0,005885794 & $-0,008572223$ & $\mathrm{~N}$ & $\mathrm{~N}$ & $\mathrm{~N}$ \\
\hline 8 & DVLA & $-0,039644236$ & 0,102564002 & $-0,006712190$ & $\mathrm{~N}$ & $\mathrm{M}$ & $\mathrm{N}$ \\
\hline 9 & KLBF & 0,018413625 & $-0,008817627$ & $-0,000327494$ & $\mathrm{~N}$ & $\mathrm{~N}$ & $\mathrm{~N}$ \\
\hline 10 & SIDO & $-0,042107873$ & $-0,075515905$ & $-0,013448790$ & $\mathrm{~N}$ & $\mathrm{~N}$ & $\mathrm{~N}$ \\
\hline 11 & WTON & $-0,136559689$ & 0,000083225 & $-0,062250679$ & $\mathrm{~N}$ & $\mathrm{~N}$ & $\mathrm{~N}$ \\
\hline 12 & ARNA & $-0,030672952$ & $-0,105937791$ & $-0,065101957$ & $\mathrm{~N}$ & $\mathrm{~N}$ & $\mathrm{~N}$ \\
\hline 13 & MARK & 0,197271754 & 0,049909369 & 0,089069792 & $\mathrm{M}$ & $\mathrm{M}$ & $\mathrm{M}$ \\
\hline 14 & SRSN & 0,001399617 & 0,033321834 & 0,037112714 & $\mathrm{~N}$ & $\mathrm{M}$ & $\mathrm{M}$ \\
\hline 15 & AUTO & 0,028430444 & $-0,052527595$ & $-0,005700715$ & $\mathrm{G}$ & $\mathrm{N}$ & $\mathrm{N}$ \\
\hline 16 & SMSM & 0,046661109 & 0,040915635 & $-0,042364598$ & $\mathrm{M}$ & $\mathrm{M}$ & $\mathrm{N}$ \\
\hline 17 & SRIL & 0,092898840 & $-0,161370591$ & 0,097567922 & $\mathrm{M}$ & $\mathrm{N}$ & $\mathrm{M}$ \\
\hline
\end{tabular}

Sumber: Data Primer yang diolah, 2021 
Dari hasil perhitungan TATA terhadap 17 perusahaan sampel pada tahun 2017 dapat diketahui bahwa 5 perusahaan tergolong manipulators, 11 perusahaan tergolong sebagai non manipulators dan 1 perusahaan tergolong sebagai grey company.

Dari hasil perhitungan TATA terhadap 17 perusahaan sampel pada tahun 2018 dapat diketahui bahwa 5 perusahaan tergolong manipulators dan 12 perusahaan tergolong sebagai non manipulators.

Tabel 7. Hasil Penggolongan Perusahaan Tahun 2017

\begin{tabular}{|c|c|c|c|c|c|c|c|}
\hline No & Emiten & DSRI & $G M I$ & $A Q I$ & $S G I$ & $T A T A$ & Kategori \\
\hline 1 & BUDI & $\mathrm{G}$ & $\mathrm{N}$ & $\mathrm{N}$ & $\mathrm{N}$ & $\mathrm{N}$ & Non Manipulators \\
\hline 2 & CLEO & $\mathrm{M}$ & $\mathrm{N}$ & $\mathrm{M}$ & $\mathrm{G}$ & $\mathrm{N}$ & Grey \\
\hline 3 & HOKI & $\mathrm{M}$ & $\mathrm{G}$ & $\mathrm{M}$ & $\mathrm{N}$ & $\mathrm{M}$ & Manipulators \\
\hline 4 & MYOR & $\mathrm{G}$ & $\mathrm{G}$ & $\mathrm{G}$ & $\mathrm{N}$ & $\mathrm{N}$ & Grey \\
\hline 5 & SKLT & $\mathrm{N}$ & $\mathrm{N}$ & $\mathrm{G}$ & $\mathrm{N}$ & $\mathrm{N}$ & Non Manipulators \\
\hline 6 & STTP & $\mathrm{N}$ & $\mathrm{N}$ & $\mathrm{N}$ & $\mathrm{N}$ & $\mathrm{M}$ & Non Manipulators \\
\hline 7 & GGRM & $\mathrm{N}$ & $\mathrm{N}$ & $\mathrm{G}$ & $\mathrm{N}$ & $\mathrm{N}$ & Non Manipulators \\
\hline 8 & DVLA & $\mathrm{N}$ & $\mathrm{N}$ & $\mathrm{G}$ & $\mathrm{N}$ & $\mathrm{N}$ & Non Manipulators \\
\hline 9 & KLBF & $\mathrm{G}$ & $\mathrm{N}$ & $\mathrm{G}$ & $\mathrm{N}$ & $\mathrm{N}$ & Non Manipulators \\
\hline 10 & SIDO & $\mathrm{G}$ & $\mathrm{N}$ & $\mathrm{N}$ & $\mathrm{N}$ & $\mathrm{N}$ & Non Manipulators \\
\hline 11 & WTON & $\mathrm{G}$ & $\mathrm{G}$ & $\mathrm{M}$ & $\mathrm{G}$ & $\mathrm{N}$ & Grey \\
\hline 12 & ARNA & $\mathrm{N}$ & $\mathrm{N}$ & $\mathrm{G}$ & $\mathrm{G}$ & $\mathrm{N}$ & Non Manipulators \\
\hline 13 & MARK & $\mathrm{G}$ & $\mathrm{N}$ & $\mathrm{M}$ & $\mathrm{G}$ & $\mathrm{M}$ & Grey \\
\hline 14 & SRSN & $\mathrm{N}$ & $\mathrm{N}$ & $\mathrm{N}$ & $\mathrm{N}$ & $\mathrm{N}$ & Non Manipulators \\
\hline 15 & AUTO & $\mathrm{G}$ & $\mathrm{G}$ & $\mathrm{G}$ & $\mathrm{N}$ & $\mathrm{G}$ & Grey \\
\hline 16 & SMSM & $\mathrm{N}$ & $\mathrm{G}$ & $\mathrm{G}$ & $\mathrm{G}$ & $\mathrm{M}$ & Grey \\
\hline 17 & SRIL & $\mathrm{G}$ & $\mathrm{N}$ & $\mathrm{M}$ & $\mathrm{N}$ & $\mathrm{M}$ & Grey \\
\hline
\end{tabular}

Sumber: Data Primer yang diolah, 2021

Berdasarkan tabel diatas dapat diketahui bahwa pada tahun 2017, 1 perusahaan digolongkan sebagai manipulators, 9 perusahaan digolongkan sebagai non manipulators dan 7 perusahaan digolongkan sebagai grey company.
Dari hasil perhitungan TATA terhadap 17 perusahaan sampel pada tahun 2019 dapat diketahui bahwa 3 perusahaan tergolong manipulators, 12 perusahaan tergolong sebagai non manipulators dan 2 perusahaan tergolong sebagai grey company.

Berdasarkan hasil perhitungan 5 rasio index terhadap 17 perusahaan sampel maka dapat disimpulkan kategori perusahaan yang akan dijelaskan dalam tabel berikut : 
Tabel 8. Hasil Penggolongan Perusahaan Tahun 2018

\begin{tabular}{|c|c|c|c|c|c|c|c|}
\hline No & Emiten & DSRI & GMI & AQI & SGI & TATA & Kategori \\
\hline 1 & BUDI & G & G & M & N & N & Grey \\
\hline 2 & CLEO & N & G & M & G & N & Grey \\
\hline 3 & HOKI & N & N & G & G & N & Non Manipulators \\
\hline 4 & MYOR & N & N & G & G & M & Grey \\
\hline 5 & SKLT & G & N & M & G & N & Grey \\
\hline 6 & STTP & G & N & M & N & N & Non Manipulators \\
\hline 7 & GGRM & N & G & N & G & N & Non Manipulators \\
\hline 8 & DVLA & G & G & N & N & M & Grey \\
\hline 9 & KLBF & G & G & G & N & N & Grey \\
\hline 10 & SIDO & N & N & N & N & N & Non Manipulators \\
\hline 11 & WTON & N & N & M & G & N & Non Manipulators \\
\hline 12 & ARNA & N & N & G & G & N & Non Manipulators \\
\hline 13 & MARK & N & N & G & G & M & Grey \\
\hline 14 & SRSN & G & N & G & G & M & Grey \\
\hline 15 & AUTO & N & G & G & N & N & Non Manipulators \\
\hline 16 & SMSM & G & N & G & G & M & Grey \\
\hline 17 & SRIL* & N & M & G & G & N & Grey \\
\hline
\end{tabular}

Sumber: Data Primer yang diolah, 2021

Berdasarkan tabel diatas dapat diketahui bahwa pada tahun 2018, 7 perusahaan digolongkan sebagai non manipulators dan 10 perusahaan digolongkan sebagai grey company.

Tabel 9. Hasil Penggolongan Perusahaan Tahun 2019

\begin{tabular}{|c|c|c|c|c|c|c|c|}
\hline No & Emiten & DSRI & GMI & $A Q I$ & $S G I$ & TATA & Kategori \\
\hline 1 & BUDI & N & G & N & N & N & Non Manipulators \\
\hline 2 & CLEO & G & N & G & G & N & Grey \\
\hline 3 & HOKI & N & N & N & G & G & Non Manipulators \\
\hline 4 & MYOR & N & N & N & N & N & Non Manipulators \\
\hline 5 & SKLT & N & N & G & G & N & Non Manipulators \\
\hline 6 & STTP & G & N & N & G & G & Grey \\
\hline 7 & GGRM & N & N & G & G & N & Non Manipulators \\
\hline 8 & DVLA & N & N & G & N & N & Non Manipulators \\
\hline 9 & KLBF & N & G & G & N & N & Non Manipulators \\
\hline 10 & SIDO & G & N & G & N & N & Non Manipulators \\
\hline 11 & WTON & G & N & G & N & N & Non Manipulators \\
\hline 12 & ARNA & N & N & G & N & N & Non Manipulators \\
\hline 13 & MARK & N & G & M & N & M & Grey \\
\hline 14 & SRSN & G & N & G & G & M & Grey \\
\hline 15 & AUTO & N & N & N & N & N & Non Manipulators \\
\hline 16 & SMSM & G & N & G & N & N & Non Manipulators \\
\hline 17 & SRIL & G & N & M & G & M & Grey \\
\hline
\end{tabular}

Sumber: Data Primer yang diolah, 2021

Berdasarkan tabel diatas dapat diketahui bahwa pada tahun 2019, 12 perusahaan digolongkan sebagai non manipulators dan 5 perusahaan digolongkan sebagai grey company.

f. Perhitungan jumlah persentase dari perusahaan yang tergolong 
manipulators, non manipulators dan grey company.

1) Perusahaan Manipulators

Perusahaan Manipulators tahun 2017

Manipulators $=\frac{1}{17} x 100 \%$

$$
=\mathbf{5}, 89 \%
$$

Perusahaan Manipulators tahun 2018

$\begin{aligned} \text { Manipulators } & =\frac{\mathbf{0}}{\mathbf{1 7}} \times 100 \% \\ & =\mathbf{0} \%\end{aligned}$

Perusahaan Manipulators tahun 2019

Manipulators $=\frac{0}{17} \times 100 \%$

$$
=\mathbf{0} \%
$$

2) Perusahaan

Non

Manipulators

Perusahaan

Non

Manipulators 2017

Non Manipulators

$$
\begin{aligned}
& =\frac{9}{17} x 100 \% \\
& =52,94 \%
\end{aligned}
$$

Perusahaan Non Manipulators 2018

Non Manipulators

$$
\begin{aligned}
& =\frac{7}{17} x 100 \% \\
& =41,17 \%
\end{aligned}
$$

Perusahaan Non Manipulators 2019

Non Manipulators

$$
\begin{aligned}
& =\frac{12}{17} x 100 \% \\
& =70,59 \%
\end{aligned}
$$

3) Perusahaan Grey Company Perusahaan Grey Company 2017

Grey $=\frac{7}{17} x 100 \%$

$$
=41,17 \%
$$

Perusahaan Grey Company 2018

$$
\begin{array}{r}
\text { Grey }=\frac{10}{17} x 100 \% \\
=58,83 \%
\end{array}
$$

Perusahaan Grey Company 2019

$$
\text { Grey }=\frac{\mathbf{5}}{\mathbf{1 7}} x 100 \%
$$

$$
=29,41 \%
$$

\section{Pembahasan}

a. Perusahaan Manipulators

Berdasarkan hasil perhitungan data dengan menggunakan lima index parameter Beneish M-Score yang dilakukan pada 17 perusahaan manufaktur selama tahun 2017-2019. Diperoleh jumlah perusahaan yang tergolong sebagai manipulators pada tahun 2017 sebanyak 1 perusahaan dengan persentase sebesar 5,89\%, sedangkan tahun 2018 dan tahun 2019 jumlahnya mengalami penurunan sehingga tidak terdapat perusahaan manipulators pada tahun tersebut.

\section{b. Perusahaan Non Manipulators}

Analisis dengan menggunakan index parameter Beneish M-Score yang dilakukan terhadap 17 perusahaan manufaktur yang terdaftar di Bursa Efek Indonesia 2017-2019. Menyatakan bahwa pada tahun 2017 terdapat 9 perusahaan yang tergolong sebagai non manipulator dengan persentase sebesar 52,94\%. Pada tahun 2018 persentase tersebut mengalami penurunan sebesar $41,17 \%$ yang diikuti dengan adanya penurunan jumlah perusahaan yang tergolong sebagai non manipulator yaitu 
sebanyak 7 perusahaan dan pada tahun 2019 persentase tersebut mengalami peningkatan yang cukup pesat sebesar $70,59 \%$ dengan jumlah 12 perusahaan yang tergolong sebagai non manipulator. Sehingga, tren yang muncul adalah adanya peningkatan persentase perusahaan yang tergolong sebagai non manipulator.

\section{c. Perusahaan Grey Company}

Berdasarkan hasil pengolahan data menggunakan lima index parameter Beneish M-Score yang dilakukan pada 17 perusahaan manufaktur selama tahun 2017-2019. Diperoleh sebanyak 7 perusahaan pada tahun 2017 yang tergolong sebagai grey company dengan persentase sebesar $41,17 \%$. Tahun 2018, persentase perusahan grey company mengalami peningkatan sebesar 58,83\% dengan jumlah 10 perusahaan sedangkan pada tahun 2019 jumlah perusahaan yang tergolong sebagai grey company mengalami penurunan menjadi 5 perusahaan dengan persentase sebesar $29,41 \%$. Perusahaan yang tergolong sebagai grey company merupakan perusahaan yang tidak tergolong sebagai non manipulator maupun manipulator.

\section{KESIMPULAN}

Penelitian ini betujuan untuk mengetahui jumlah dan persentase perusahaan manufaktur yang listing di Bursa Efek Indonesia (BEI) Tahun
2017-2019 yang tergolong manipulators, non manipulators atau grey company. Analisis yang dilakukan dalam mendeteksi kecurangan laporan keuangan menggunakan lima rasio signifikan dari Beneish Ratio Index. Lima rasio tersebut adalah Days Sales in Receivable Index (DSRI), Gross Margin Index (GMI), Asset Quality Index (AQI), Sales Growth Index (SGI) dan Total Accruals to Total Assets Index (TATA). Sampel diambil dengan cara metode non probability purposive judgement sampling, yaitu peneliti memiliki suatu kriteria dalam menentukan sampel dan memiliki keterbatasan generalisasi. Hasil dari penelitian ini antara lain:

1. Perusahaan Manipulators

Analisis kecurangan laporan keuangan menggunakan Beneish $M$ Score pada tahun 2017 mencatat bahwa 1 perusahaan atau 5,89\% dari total perusahaan sampel telah tergolong sebagai manipulators. Perusahaan yang tergolong dalam kategori perusahaan Manipulators memiliki indikasi melakukan fraud (kecurangan) terhadap penyajian laporan keuangannya. Sebaliknya pada tahun 2018 dan 2019 tidak terdapat perusahaan yang tergolong sebagai manipulators. Hal ini menunjukkan bahwa perusahaan tidak melakukan kecurangan dalam pembuatan laporan keuangan. 
2. Perusahaan Non-Manipulators

Analisis kecurangan laporan keuangan menggunakan Beneish MScore pada tahun 2017 terdapat 9 perusahaan atau 52,94\%, tahun 2018 terdapat 7 perusahaan atau $41,17 \%$, tahun 2019 terdapat 12 perusahaan atau $70,59 \%$ dari total perusahaan sampel yang tergolong nonmanipulators. Hal ini menunjukkan perusahaan memiliki komitmen untuk menyajikan laporan keuangan yang tidak menyesatkan para pengguna laporan keuangan yang memiliki kepentingan terhadap laporan keuangan perusahaan.

\section{Perusahaan Grey Company}

Analisis kecurangan laporan keuangan menggunakan Beneish MScore pada tahun 2017 terdapat 7 perusahaan atau $41,17 \%$, tahun 2018 terdapat 10 atau 58,83\%, tahun 2019 terdapat 5 atau $29,41 \%$ dari total perusahaan sampel tersebut yang tergolong sebagai grey company. Perusahaan ini tidak digolongkan sebagai manipulators atau non manipulators. Grey company memiliki indikasi melakukan kecurangan laporan keuangan namun dalam jumlah yang tidak signifikan.

$$
\text { Penelitian selanjutnya }
$$

diharapkan dapat memperluas sampel penelitian, sehingga tidak terbatas hanya pada satu sektor saja dan memilih periode tahun pengamatan yang lebih panjang dari yang penulis gunakan agar hasil yang di dapat lebih akurat.
Penelitian selanjutnya juga diharapkan dapat menghitung tingkat signifikansi dari tiap variabelvariabel akuntansi, sehingga dapat diketahui mana variabel yang secara signifikan mampu membedakan antara perusahaan manipulators, non manipulators dan grey company.

\section{DAFTAR PUSTAKA}

ACFE. (2018). 2018 Report to Nations: Global Study on Occupational Fraud and Abuse.

http://www.acfe.com/report-tothenations/2018/

ACFE Indonesia Chapter \#111. (2016). Survai Fraud Indonesia. https://acfeindonesia.or.id/surveifraudindonesia/

Bursa Efek Indonesia. (n.d.). www.idx.co.id

Christy, Y. ., \& Stephanus, D. S. (2018). Pendeteksian Kecurangan Laporan Keuangan Dengan Beneish MScore Pada Perusahaan Perbankan Terbuka. Jurnal Akuntansi Bisnis, Vol 16, No.

Djarwanto. (2010). Pokok-pokok Analisa Laporan Keuangan. BPFE.

Hantono. (2018). Analisis Pendeteksian Financial Statement Fraud dengan Pendekatan Model Beneish pada Perusahaan BUMN. Jurnal Riset Akuntansi Going Concern, 254-269.

Nasution, M. I. P., N, N., N, N., Rahma, T. I. F., \& K, K. (2020). Face Recognition Login Authentication for Digital Payment Solution at 
COVID-19 Pandemic. 2020

3rd International Conference

on Computer and Informatics Engineering (IC2IE) Face, 48-

51.

https://doi.org/0.1109/IC2IE50 715.2020 .9274654 .

Priantara, D. (2013). Fraud Auditing \& Investigation. Mitra Wacana Media.

Sujarweni, V. W. (2017). Analisis

Laporan Keuangan. Pustaka Baru Press. 